\title{
Functional promoter polymorphisms of macrophage migration inhibitory factor in peptic ulcer diseases
}

\author{
HISAKAZU SHIROEDA ${ }^{1}$, TOMOMITSU TAHARA ${ }^{2}$, TOMOYUKI SHIBATA ${ }^{2}$, MASAKATSU NAKAMURA ${ }^{2}$ \\ HIDETO YAMADA ${ }^{1}$, TOMOE NOMURA ${ }^{1}$, RANJI HAYASHI ${ }^{1}$, TAKASHI SAITO ${ }^{1}$, TOMOKI FUKUYAMA ${ }^{1}$, \\ TOSHIMI OTSUKA ${ }^{1}$, HIROKAZU YANO ${ }^{1}$, KAZUAKI OZAKI ${ }^{1}$, MUTSUMI TSUCHISHIMA ${ }^{1}$, \\ MIKIHIRO TSUTSUMI ${ }^{1}$ and TOMIYASU ARISAWA ${ }^{1}$ \\ ${ }^{1}$ Department of Gastroenterology, Kanazawa Medical University; 1-1 Daigaku, Uchinada-machi, \\ Ishikawa 920-0293; ${ }^{2}$ Department of Gastroenterology, Fujita Health University, 1-98, \\ Dengakugakubo, Kutsukake-cho, Toyoake 470-1192, Japan
}

Received June 1, 2010; Accepted August 16, 2010

DOI: 10.3892/ijmm_00000517

\begin{abstract}
Macrophage migration inhibitory factor (MIF) is a key proinflammatory mediator, which plays a pivotal role in inflammatory and immune diseases. We attempted to clarify the association of functional polymorphisms of MIF gene promoter with the development of gastro-duodenal ulcer. The study was performed in 471 stocked DNAs obtained from the subjects, including 93 healthy volunteers, with no evidence of gastric malignancy. We employed the PCR-SSCP method to detect gene polymorphisms. In all 471 DNAs, 92 and 43 were obtained from gastric and duodenal ulcer patients, respectively. By an unadjusted analysis, infection with Helicobacter pylori (H. pylori), male gender and non-steroidal anti-inflammatory drug (NSAID/aspirin) use were significantly associated with a risk for developing a gastric ulcer, whereas MIF promoter polymorphisms were not. On the other hand, infection with $H$. pylori, male gender and 7CATT repeat at position -794 were significantly associated with the development of a duodenal ulcer, whereas NSAID/ aspirin use was not. By the analysis after adjustment for age, gender, NSAID/aspirin use and $H$. pylori infection status, 7/7-CATT homozygote had a significantly increased risk for the development of duodenal ulcers (OR, 6.31; 95\% CI, 1.5026.6; $\mathrm{p}=0.012$ ). No factors were significantly associated with the development of peptic ulcers in NSAID/aspirin users. Our results suggested that tetranucleotide repeat polymorphism of MIF gene promoter might be associated with the development of duodenal ulcers.
\end{abstract}

Correspondence to: Dr Tomiyasu Arisawa, Department of Gastroenterology, Kanazawa Medical University, 1-1 Daigaku, Uchinada-machi, Ishikawa 920-0293, Japan

E-mail: tarisawa@kanazawa-med.ac.jp

Key words: macrophage migration inhibitory factor, promoter polymorphism, peptic ulcer, Helicobacter pylori, non-steroidal antiinflammatory drug

\section{Introduction}

It is well known that Helicobacter pylori (H. pylori) infection, as well as non-steroidal anti-inflammatory drug (NSAID/ aspirin) use, are major contributing factors to the development of peptic ulcers (1). Infection with $H$. pylori usually leads to persistent colonization and chronic gastric inflammation. However, there are marked differences in the extent of inflammation among $H$. pylori-infected patients, so clinical consequences only develop in a small subgroup. The course of $H$. pylori infection may be influenced by bacterial virulence factors, as well as by genetic predisposition and host immunity. Inflammation induced by $H$. pylori is implicated in gastric mucosal damage and characterized by severe granulocytic and lymphocytic infiltration (2). Although the T helper cell response to $H$. pylori is considered to be dependent on type 1 helper (Th1) cells, the factors influencing this immune response to $H$. pylori infection are largely unknown. Important cytokines that are related to Th1-mediated responses and are upregulated during chronic $H$. pylori infection include interferon- $\gamma$, tumor necrosis factor, and interleukin-1ß (3-5).

Macrophage migration inhibitory factor (MIF) was originally identified as an activity isolated from $\mathrm{T}$ lymphocytes that is capable of inhibiting the random migration of macrophages $(6,7)$. The human MIF cDNA was finally cloned in 1989 (8). MIF is a key proinflammatory mediator, which plays a pivotal role in inflammatory and immune diseases (9-11). It contributes toward an excessive inflammatory response both directly via an induction of proinflammatory cytokine secretion (12) and indirectly through its ability to override the anti-inflammatory activity of glucocorticoids (13). Xia et al hve reported that $H$. pylori infection increased MIF expression in both gastric inflammatory and epithelial cells (14), thus MIF may play an important role in $H$. pylorirelated gastric inflammation and ulceration.

Polymorphisms with potential functional relevance have been identified in the MIF gene promoter, an SNP at position -173 (G to C) (15) and a tetranucleotide CATT repeat beginning at nucleotide position -794 (16) have been found to be associated with altered levels of MIF gene transcription 
in vitro. It has been demonstrated that the functional importance of these variants includes findings of significant association with several immune-mediated inflammatory diseases (15-17). We have already reported the close association between MIF promoter polymorphisms and gastric mucosal atrophy followed by gastric carcinogenesis $(18,19)$. However, the roles of these polymorphisms in the development of gastro-duodenal peptic ulceration remain unclear.

In the present study, we attempted to clarify the associations of G-173C and -794 CATT repeat in MIF gene promoter with the development of gastro-duodenal ulcers.

\section{Materials and methods}

Clinical samples. We randomly selected 386 samples from our stocked DNA obtained from patients enrolled the Endoscopy Center of Fujita Health University Hospital between 2006-2009. All patients underwent upper gastrointestinal endoscopy and, in some patients, biopsy specimens were taken from antral mucosa. Parts of each specimen was fixed in $10 \%$ buffered formalin and embedded in paraffin, while the other part was immediately frozen and stored at $-80^{\circ} \mathrm{C}$. Finally, the study population comprised 471 subjects, including 93 healthy volunteers, with no neoplastic lesions whose DNA was clearly analyzed.

H. pylori infection status was assessed by serology, histological examination, or the urea breath test. Patients were diagnosed as having an infection when at least one of the diagnostic tests was positive.

The Ethics Committee of Fujita Health University School of Medicine approved the protocol, and written informed consent was obtained from all participating subjects.

Genotyping of polymorphisms. Sample stocked DNAs isolated from biopsy specimens or peripheral blood were used. Polymorphism was genotyped by PCR-SSCP method as reported previously $(18,19)$. To detect -794 CATT repeats, using the primer pair (MIFTRF, 5'-TGATCCAGTTGCTGCCTTGTC-3', and MIFTRR, 5'-TCCACTAATGGTAAACTCGGGGAC-3'), PCR was carried out in a volume of $20 \mu \mathrm{l}$ containing $0.1 \mu \mathrm{g}$ of genomic DNA. DNA was denatured at $95^{\circ} \mathrm{C}$ for $3 \mathrm{~min}$, followed by 35 cycles at $95^{\circ} \mathrm{C}$ for $30 \mathrm{sec}, 62^{\circ} \mathrm{C}$ for $40 \mathrm{sec}$, and $72^{\circ} \mathrm{C}$ for $45 \mathrm{sec}$, with final extension at $72^{\circ} \mathrm{C}$ for $5 \mathrm{~min}$. Thereafter, $2 \mu \mathrm{l}$ of the PCR product was denatured with $10 \mu \mathrm{l}$ of formamide (Sigma-Aldrich Co., St. Louis, USA) at $90^{\circ} \mathrm{C}$ for $5 \mathrm{~min}$. SSCP was carried out at $6^{\circ} \mathrm{C}$ using a GenePhor DNA separation system with GeneGel Excel 12.5/24 (GE Healthcare, USA), after which the denatured single strand DNA bands were detected using a DNA Silver Staining Kit (GE Healthcare).

To detect G-173C polymorphism, using the primer set (MIF173F, 5'-TCTAGCCGCCAAGTGGAGAACA-3' and MIF173R, 5'-ACTGTGGTCCCGCCTTTTGTGA-3'), PCR reaction was carried out with $60^{\circ} \mathrm{C}$ annealing temperature as described above. SSCP was also carried out as described above.

Statistical analysis. The data of age were expressed as mean $\pm \mathrm{SD}$. Mean ages between 2 groups were compared with Student's t-test. Allele and genotype frequencies were calculated by direct counting. The allele counts were compared by a $2 \times 2$ table using Chi-squared test. The strength of association between allele frequencies and the disease was assessed by calculating the odds ratio (OR) and $95 \%$ confidence intervals (CI) by logistic regression analysis using genotype as a variate or the number of allele as a co-variate. Adjusted ORs were calculated with the use of a regression analysis after adjustment for age, gender, NSAIDs/aspirin use and $H$. pylori infection status. For all analyses, the level of significance was set at $\mathrm{p}<0.05$.

\section{Results}

Characteristics of subjects and frequencies of genotypes. Single strand DNAs of both -794 repeat and G-173C genotypes were clearly separated by $\operatorname{SSCP}(18,19)$. A single strand band of 8-CATT repeat was not detected in any of the 471 subjects. These polymorphisms were in significant linkage disequilibrium, with the $-173 \mathrm{C}$ allele strongly associated with the 7-CATT repeat allele. The most frequent haplotypes were -173G/ 5-CATT, -173G/6-CATT and -173C/7-CATT, which constituted $\sim 90 \%$ of haplotypes.

In the 471 subjects, there were 135 with peptic ulcer (92 with gastric ulcer and 43 with duodenal ulcer, Table I). Compared with the non-ulcer group including 93 volunteers, mean age, male/female ratio and $H$. pylori positivity were higher in the ulcer group. The frequencies of n-CATT and -173C alleles were not significantly different between the 2 groups.

Association between MIF promoter polymorphisms and peptic ulcer. By the unadjusted analysis, male gender, H. pylori infection, NSAID/aspirin use and 7-CATT repeat were significantly associated with the development of peptic ulcers (Table II). Infection with H. pylori, male gender and NSAID/aspirin use were significantly associated with a risk for the development of gastric ulcers, whereas MIF promoter polymorphisms were not. On the other hand, infection with $H$. pylori, male gender and 7-CATT repeat were significantly associated with the development of duodenal ulcers, whereas NSAIDs/aspirin use were not.

By the analysis after adjustment for age, gender, NSAID/ aspirin use and $H$. pylori infection status, 7/7-CATT homozygote had a significantly increased risk for the development of duodenal ulcers (OR, 6.31; 95\%CI, 1.50-26.6; $\mathrm{p}=0.012$; Table III).

Association between MIF promoter polymorphisms and peptic ulcer in NSAID/aspirin users. There were 47 NSAIDs/aspirin users, 24 subjects with peptic ulcer (18 with gastric ulcer and 6 with duodenal ulcer), of all 471 subjects. As shown in Table IV, male gender, infection with $H$. pylori and MIF promoter polymorphism were not significantly associated with a risk for the development of peptic ulcer disease in NSAID/aspirin users.

\section{Discussion}

Results from our study suggested that 7-CATT repeat of MIF gene promoter at a position -794 was significantly associated with a risk for the development of peptic ulcers, especially duodenal ulcer. In addition, this polymorphism did not appear to affect the developing NSAID/aspirin-induced ulcer. 
Table I. Characteristics of the subjects and frequency of genotypes.

\begin{tabular}{|c|c|c|c|c|}
\hline & Non-ulcer & Peptic ulcer & Gastric ulcer & Duodenal ulcer \\
\hline $\mathrm{n}$ & 336 & 135 & 92 & 43 \\
\hline Mean age \pm SD & $52.6 \pm 19.7$ & $62.7 \pm 13.6$ & $65.5 \pm 11.7$ & $56.9 \pm 15.6$ \\
\hline Male:female & $180: 156$ & $102: 33$ & $70: 22$ & $32: 11$ \\
\hline HP positive rate & $55.6 \%$ & $82.7 \%$ & $85.6 \%$ & $76.7 \%$ \\
\hline \multicolumn{5}{|l|}{ n-CATT repeat } \\
\hline $5 / 5$ & 53 & 17 & 11 & 6 \\
\hline $5 / 6$ & 112 & 41 & 28 & 13 \\
\hline $5 / 7$ & 47 & 14 & 11 & 3 \\
\hline $6 / 6$ & 61 & 24 & 17 & 7 \\
\hline $6 / 7$ & 56 & 30 & 20 & 10 \\
\hline $7 / 7$ & 7 & 9 & 5 & 4 \\
\hline 5-CATT frequency & $39.4 \%$ & $33.0 \%$ & $33.2 \%$ & $32.6 \%$ \\
\hline 6-CATT frequency & $43.2 \%$ & $44.1 \%$ & $44.6 \%$ & $43.0 \%$ \\
\hline 7-CATT frequency & $17.4 \%$ & $23.0 \%$ & $22.3 \%$ & $24.4 \%$ \\
\hline \multicolumn{5}{|l|}{ G-173C genotype } \\
\hline $\mathrm{G} / \mathrm{G}$ & 207 & 77 & 53 & 24 \\
\hline $\mathrm{G} / \mathrm{C}$ & 111 & 46 & 31 & 15 \\
\hline $\mathrm{C} / \mathrm{C}$ & 18 & 12 & 8 & 4 \\
\hline$-173 \mathrm{C}$ frequency & $21.9 \%$ & $25.9 \%$ & $25.5 \%$ & $26.7 \%$ \\
\hline
\end{tabular}

Table II. Association between gastro-duodenal ulcer and various risk factors.

\begin{tabular}{lccc}
\hline & & OR (95\% confidence intervals) \\
\cline { 2 - 4 } Variables & Peptic ulcer & Gastric ulcer & Duodenal ulcer \\
\hline 5/5-CATT & $0.77(0.43-1.38)$ & $0.73(0.36-1.45)$ & $0.87(0.35-2.15)$ \\
$7 / 7-C A T T$ & $3.36(1.22-9.21)^{\mathrm{a}}$ & $2.70(0.84-8.72)$ & $4.82(1.35-17.2)^{\mathrm{c}}$ \\
No. of 7-CATTd & $1.42(1.00-2.02)^{\mathrm{b}}$ & $1.38(0.91-2.08)$ & $1.56(0.90-2.68)$ \\
-173 C/C & $1.72(0.81-3.68)$ & $1.45(0.59-3.54)$ & $1.81(0.58-5.63)$ \\
Male gender & $2.68(1.71-4.19)$ & $2.76(1.63-4.66)$ & $2.52(1.23-5.17)$ \\
NSAIDs/aspirin use & $2.94(1.60-5.42)$ & $3.31(1.70-6.45)$ & $2.21(0.84-5.77)$ \\
H. pylori infected & $3.82(2.28-6.40)$ & $4.74(2.49-8.97)$ & $2.64(1.24-5.59)$ \\
\hline
\end{tabular}

${ }^{\mathrm{a}} \mathrm{p}=0.019 ;{ }^{\mathrm{b}} \mathrm{p}=0.015 ;{ }^{\mathrm{c}} \mathrm{p}=0.049$ by unadjusted analysis; ${ }^{\mathrm{d}}$ analyses were performed using the number of 7 -CATT allele as a co-variate.

Table III. Association between gastro-duodenal ulcer and MIF gene polymorphisms.

\begin{tabular}{lccc}
\hline & & OR $(95 \%$ confidence intervals $)$ \\
\cline { 2 - 4 } Variables & Peptic ulcer & Gastric ulcer & Duodenal ulcer \\
\hline 5/5-CATT & $0.93(0.48-1.83)$ & $0.88(0.40-1.94)$ & $0.98(0.36-2.65)$ \\
7/7-CATT & $3.06(0.98-9.56)$ & $2.38(0.63-9.01)$ & $6.31(1.50-26.6)^{\mathrm{a}}$ \\
No. of 7-CATT & $1.40(0.94-2.09)$ & $1.40(0.87-2.23)$ & $1.43(0.79-2.58)$ \\
-173 C/C & $1.35(0.58-3.11)$ & $1.21(0.47-3.15)$ & $1.79(0.53-6.05)$ \\
\hline
\end{tabular}

Logistic regression analysis after adjustment for age, gender, NSAIDs/aspirin use and $H$. pylori infection status; ${ }^{\mathrm{a}} \mathrm{p}=0.012$; ${ }^{\text {analyses }}$ were performed using the number of 7-CATT allele as a co-variate. 
Table IV. Association between gastro-duodenal ulcer and various risk factors in NSAIDs/aspirin users.

\begin{tabular}{lcc}
\hline & \multicolumn{2}{c}{ OR (95\% confidence intervals) } \\
\cline { 2 - 4 } & Unadjusted OR & Adjusted OR variables $^{\mathrm{a}}$ \\
\hline 5/5-CATT & $0.96(0.12-7.41)$ & $1.04(0.11-10.3)$ \\
7/7-CATT & $0.96(0.12-7.41)$ & $1.94(0.21-18.0)$ \\
No. of 7-CATT & $1.29(0.52-3.15)$ & $1.76(0.64-4.84)$ \\
-173 C/C & $0.61(0.092-4.01)$ & $0.93(0.12-7.51)$ \\
Male gender & $2.60(0.80-8.49)$ & - \\
H.pylori infected & $1.10(0.34-3.55)$ & - \\
\hline
\end{tabular}

aAdjusted for gender, age, H. pylori infection status; banalyses were performed using the number of 7-CATT allele as a co-variate.

It is generally believed that MIF functions as a cytokine to promote the recruitment of neutrophils and macrophages and the migration of these cells to the site of inflammation (20). MIF is involved in T-cell proliferation through promoting the secretion of interleukin-2 (21) and can deliver a priming signal to neutrophils to mobilize them to produce an immediate and robust response in the presence of pathogens (22). In addition, MIF can induce the production of tumor necrosis factor (TNF) and inducible nitric oxide (iNOS) (23). Many studies have shown MIF to be a key modulator of many chronic and disabling human disorders, such as rheumatoid arthritis (24), sepsis (25), acute respiratory syndrome (26), and atopic diseases $(27,28)$. An important role of MIF on gastric disorders has been also shown, such as gastric inflammation (14), ulcer (23) and carcinogenesis (29). However, there is no report regarding the association between MIF gene promoter functional polymorphisms and gastric disorders, although several studies have shown significant associations of these polymorphisms with cystic fibrosis (30), psoriasis (31), and atopic disorders (32).

Baugh et al have reported the correlation of -794 5-CATT repeat with low disease severity in rheumatoid arthritis patients (17) and Hizawa et al have also reported an increased risk of non -794 5-CATT carriers for atopy (32). Donn et al have demonstrated that $-173 \mathrm{C} /-794$ 7-CATT haplotype is of importance in susceptibility to psoriasis (15). Thus, 5-CATT seems to correlate with low inflammation severity, whereas 7-CATT seems to be associated with an increased risk for inflammation. These findings support our results that 7-CATT repeat is associated with the development of peptic ulcers.

Promoter sequence analysis indicates that the $-173 \mathrm{C}$ allele creates a potential activator protein 4 transcription factor binding site (15) and levels of MIF expression significantly differed among G-173C genotypes in a cell-type manner. Regarding CATT repeats, the 5-CATT allele was shown to be associated with lower basal and stimulated MIF promoter activity in vitro than 6-, 7- and 8-CATT alleles (16). Donn et al have shown that increasing CATT repeat with the $-173 \mathrm{C}$ allele significantly increased the promoter activity in a $\mathrm{T}$ lymphoblast cell line (15). Thus, -173C allele and 7-CATT seemed to promote the production of MIF, subsequently 7-CATT may produce the development of peptic ulcers.

In our results, $H$. pylori infection and male gender were significantly associated with the development of both gastric and duodenal ulcers. On the other hand, MIF promoter polymorphisms were associated with the duodenal ulcer and NSAID/aspirin use was an increased risk for the gastric ulcer. After age, gender, H. pylori infection and NSAID/aspirin use were controlled, there was a significant association between 7/7-CATT homozygote and the presence of duodenal ulcer. This fact suggests that tetranucleotide repeats of MIF gene promoter is an independent factor in the pathogenesis of duodenal ulcer. Gastric and duodenal ulcers share many common features including pathogenesis, diagnosis, and treatment, but several factors distinguish the two. As for duodenal ulcers, the majority of gastric ulcers can be attributed to either H. pylorior NSAID-induced mucosal damage. Gastric ulcers tend to occur later in life than duodenal ulcers. Duodenal ulcer has more positive correlation with antral gastritis than gastric ulcer (33). The exact mechanism of the formation of peptic ulcers is beyond the scope of this study. However, the effects of the MIF gene polymorphism on the formation of peptic ulcers were thought to depend on whether ulcers occur in the stomach or the duodenum.

Interestingly, no factors, including male gender, $H$. pylori infection and MIF gene polymorphisms, were significantly associated with the development of peptic ulcers in NSAID/ aspirin users. NSAID/aspirin induce gastric mucosal damage, including bleeding, ulceration, and perforation (34). These effects are caused by the inhibition of cyclooxygenase, which catalyses the formation of prostaglandin from arachidonic acid (35). That is, the pathogenetic mechanisms of ulcer formation distinguish between $H$. pylori infection and NSAID/aspirin use. Moreover, it has been reported that NSAIDs suppressed the expression of MIF (36). Therefore, we think that MIF gene polymorphisms were not associated with the development of NSAID/aspirin-induced ulcer.

In conclusion, tetranucleotide repeat polymorphism of MIF gene promoter might be associated with the development of peptic ulcer, especially duodenal ulcer. However, there seemed to be no association between this polymorphism and NSAID/aspirin-induced ulcer.

\section{References}

1. Wolfe MM, Lichtenstein DR and Singh G: Gastrointestinal toxicity of nonsteroidal antiinflammatory drugs. N Engl J Med 340: 1888-1899, 1999. 
2. Bodger K and Crabtree JE: Helicobacter pylori and gastric inflammation. Br Med Bull 54: 139-150, 1998.

3. Yamaoka Y, Kita M, Kodama T, Sawai N, Kashima K and Imanishi J: Induction of various cytokines and development of severe mucosal inflammation by CagA positive Helicobacter pylori strains. Gut 41: 442-451, 1997.

4. Rad R, Gerhard M, Lang R, et al: The Helicobacter pylori blood group antigen-binding adhesion facilitates bacterial colonization and augments a nonspecific immune response. J Immunol 168: 3033-3041, 2002.

5. Shibata J, Goto H, Arisawa T, et al: Regulation of tumour necrosis factor (TNF) induced apoptosis by soluble TNF receptors in Helicobacter pylori infection. Gut 45: 24-31, 1999.

6. Bloom BR and Bennett B: Mechanism of a reaction in vitro associated with delayed-type hypersensitivity. Science 153: 80-82, 1966

7. David JR: Delayed hypersensitivity in vitro: its mediation by cell-free substances formed by lymphoid cell-antigen interaction. Proc Natl Acad Sci USA 56: 72-77, 1966.

8. Weiser WY, Temple PA, Witek-Giannotti JS, Remold HG, Clark SC and David JR: Molecular cloning of a cDNA encoding a human macrophage migration inhibitory factor. Proc Natl Acad Sci USA 86: 7522-7526, 1989.

9. Lue H, Kleemann R, Calandra T, Roger $\mathrm{T}$ and Bernhagen J: Macrophage migration inhibitory factor (MIF): Mechanisms of action and role in disease. Microb Infect 4: 449-460, 2002.

10. De Jong YP, Abadia-Molina AC, Satoskar AR, et al: Development of chronic colitis is dependent on the cytokine MIF. Nat Immunol 2: 1061-1066, 2001.

11. Kumagi T, Akbar F, Horiike N and Onji M: Increased serum levels of macrophage migration inhibitory factor in alcoholic liver diseases and their expression in liver tissues. Clin Biochem 34: 189-193, 2001.

12. Calandra T, Echtenacher B, Roy DL, et al: Protection from septic shock by neutralization of macrophage migration inhibitory factor. Nat Med 6: 164-170, 2000

13. Donnelly SC, Haslett C, Reid PT, et al: Regulatory role for macrophage migration inhibitory factor in acute respiratory distress syndrome. Nat Med 3: 320-323, 1997

14. Xia HH, Lam SK, Huang XR, et al: Helicobacter pylori infection is associated with increased expression of macrophage migration inhibitory factor by epithelial cells, $T$ cells and macrophages in gastric mucosa. J Infect Dis 190: 293-302, 2004.

15. Donn R, Alourfi Z, De Benedetti F, et al: Mutation screening of the macrophage migration inhibitory factor gene: positive association of a functional polymorphism of macrophage migration inhibitory factor with juvenile idiopathic arthritis. Arthritis Rheum 46: 2402-2409, 2002.

16. Amoli MM, Donn RP, Thomson W, et al: Macrophage migration inhibitory factor gene polymorphism is associated with sarcoidosis in biopsy proven erythema nodosum. J Rheumatol 29: 1671-1673, 2002.

17. Baugh JA, Chitnis S, Donnelly SC, et al: A functional promoter polymorphism in the macrophage migration inhibitory factor (MIF) gene associated with disease severity in rheumatoid arthritis. Genes Immun 3: 170-176, 2003.

18. Arisawa T, Tahara T, Shibata T, et al: Functional polymorphisms in the promoter region of macrophage migration inhibitory factor and chronic gastritis. Int J Mol Med 20: 539-544, 2007.

19. Arisawa T, Tahara T, Shibata T, et al: Functional promoter polymorphisms of the macrophage migration inhibitory factor gene in gastric carcinogenesis. Oncol Rep 19: 223-228, 2008.
20. Swope MD and Lolis E: Macrophage migration inhibitory factor: cytokine, hormone, or enzyme? Rev Physiol Biochem Pharmacol 139: 1-32, 1999.

21. Bacher M, Metz CN, Calandra T, et al: An essentiaI role for MIF in T cell activation. Proc Natl Acad Sci USA 93: 7849-7854, 1996.

22. Swope M, Sun HW, Blake P and Lolis E: Direct link between cytokine activity and a catalytic site for macrophage migration inhibitory factor. EMBO J 17: 3534-3541, 1998.

23. Huang XR, Chun Hui CW, Chen YX, et al: Macrophage migration inhibitory factor is an important mediator in the pathogenesis of gastric inflammation in rats. Gastroenterology 121: 619-630, 2001.

24. Leech M, Metz C, Hall P, et al: Macrophage migration inhibitory factor in rheumatoid arthritis: evidence of proinflammatory function and regulation by glucocorticoids. Arthritis Rheum 42: $1601-1608,1999$

25. Bernhagen J, Calandra $T$ and Bucala R: The emerging role of MIF in septic shock and infection. Biotherapy 8: 123-127, 1995.

26. Donnelly SC, Bucala R, Metz CN, Grant IS, Robertson CR and Haslett C: Macrophage migration inhibitory factor and acute lung injury. Chest 116: 111S, 1999.

27. Tulic MK, Wale JL, Holt PG and Sly PD: Modification of the inflammatory response to allergen challenge after exposure to bacterial lipopolysaccharide. Am J Respir Cell Mol Biol 22: 604-612, 2000.

28. Gereda JE, Leung DY, Thatayatikom A, et al: Relation between house-dust endotoxin exposure, type-1 T-cell development, and allergen sensitization in infants at high risk of asthma. Lancet 355: $1680-1683,2000$

29. He XX, Yang J, Ding YW, Liu W, Shen QY and Xia HH: Increased epithelial and serum expression of macrophage migration inhibitory factor (MIF) in gastric cancer: potential role of MIF in gastric carcinogenesis. Gut 55: 797-802, 2006.

30. Plant BJ, Gallagher CG, Bucala R, et al: Cystic fibrosis, disease severity, and a macrophage migration inhibitory factor polymorphism. Am J Respir Crit Care Med 172: 1412-1415, 2005.

31. Donn RP, Plant D, Jury F, et al: Macrophage migration inhibitory factor gene polymorphism is associated with psoriasis. J Invest Dermatol 123: 484-487, 2004.

32. Hizawa N, Yamaguchi E, Takahashi D, Nishihara J and Nishimura M: Functional polymorphisms in the promoter region of macrophage migration inhibitory factor and atopy. Am J Respir Crit Care Med 169: 1014-1018, 2004

33. Bayyurt N, Abasiyanik MF, Sander E and Salih BA: Canonical correlation analysis of factors involved in the occurrence of peptic ulcers. Dig Dis Sci 52: 140-146, 2007.

34. Garcia Rodriguez LA and Jick H: Risk of upper gastrointestinal bleeding and perforation associated with individual non-steroidal anti-inflammatory drugs. Lancet 343: 769-772, 1994.

35. McCarthy DM: Mechanisms of mucosal injury and healing: the role of non-steroidal anti-inflammatory drugs. Scand J Gastroenterol (Suppl) 208: 24-29, 1995.

36. Xia HH, Zhang ST, Lam SK, Lin MC, Kung HF and Wong BC: Expression of macrophage migration inhibitory factor in esophageal squamous cell carcinoma and effects of bile acids and NSAIDs. Carcinogenesis 26: 11-15, 2005. 